\title{
TESTING FOR INDEPENDENCE OF OBSERVATIONS IN ANIMAL MOVEMENTS ${ }^{1}$
}

\author{
Robert K. Swihart and Norman A. Slade \\ Museum of Natural History and Department of Systematics and Ecology, \\ University of Kansas, Lawrence, Kansas 66045 USA
}

\begin{abstract}
Many analyses of animal movements assume that an animal's position at time $t+1$ is independent of its position at time $t$, but no statistical procedure exists to test this assumption with bivariate data. Using empirically derived critical values for the ratio of mean squared distance between successive observations to mean squared distance from the center of activity, we demonstrate a bivariate test of the independence assumption first proposed by Schoener. For cases in which the null hypothesis of independence is rejected, we present a procedure for determining the time interval at which autocorrelation becomes negligible. To illustrate implementation of the test, locational data obtained from a radio-tagged adult female cotton rat (Sigmodon hispidus) were used. The test can be used to design an efficient sampling schedule for movement studies, and it is also useful in revealing behavioral phenomena such as home range shifting and any tendency of animals to follow prescribed routes in their daily activities. Further, the test may provide a means of examining how an animal's use of space is affected by its internal clock.
\end{abstract}

Key words: cotton rat; home range; independence; Markov process; movements; radiotelemetry; Sigmodon hispidus; spatial analysis.

\section{INTRODUCTION}

Independence between successive observations is an implicit assumption in most statistical analyses of animal movements (Hayne 1949, Calhoun and Casby 1958, Jennrich and Turner 1969, Metzgar 1972, Koeppl et al. 1975, 1977, Wierzbowska 1975), yet this assumption is rarely addressed by ecologists studying the spatial dynamics of organisms (Anderson 1982, Don and Rennolls 1983). Stated simply, independence results when an animal's position in its home range at time $t+k$ is not a function of its position at time $t$. In studies characterized by relatively long intervals between locational observations, independence of successive observations is likely to be achieved (although temporal rhythmicity in movements may reduce this likelihood). However, frequent monitoring of an individual's location via radiotelemetry or direct observation severely jeopardizes the validity of the independence assumption (Dunn and Gipson 1977). Because frequent successive observations will tend to be positively correlated, sample variances of locations will be underestimates of the true values, and statistical estimates of home range size will underestimate the true size of the home range by an amount related to the covariance between successive observations. Nonstatistical home range measures (e.g., minimum area or boundary strip methods; see Stickel 1954) are not affected by dependent data in this manner.

Dunn and Gipson (1977) presented a sophisticated procedure for dealing with dependent locational observations. They assumed that successive locations were dependent observations from a bivariate normal dis-

\footnotetext{
${ }^{1}$ Manuscript received 4 May 1984; accepted 31 October 1984.
}

tribution with fixed mean (center of activity) and variance-covariance matrix; that is, the animals occupied stable home ranges during the observation period. Using the additional assumption that the observations followed a Markov (i.e., first-order autoregressive) process, Dunn and Gipson (1977) derived estimators of the center of activity, confidence regions for location, and measures of interanimal correlation in movements.

We chose to follow Schoener's (1981) suggestion of a simpler approach to the study of independence that seems reasonably robust to the actual distribution of activity within the home range. First, we present a test of the null model of independence. When dependence is implied by this test, we suggest a procedure for determining the time interval necessary to yield observations that can be considered independent. Observations separated by this minimum time interval can then be analyzed by traditional statistical methods.

\section{MARKoV PROCESSES AND \\ MEASURES OF INDEPENDENCE}

Several statistics have been proposed to measure adherence to a Markov process. The best known of these is the Durbin-Watson statistic, which is used to detect autocorrelated error terms in regression analysis (Durbin and Watson 1971, Chatterjee and Price 1977). The Durbin-Watson statistic is a special case of what is sometimes referred to as von Neumann's ratio (Bulmer 1975). Von Neumann (1941) considered $n$ successive observations from a normal population with mean $\mu_{X}$ and variance $\sigma_{X}{ }^{2}$. Using the (slightly) biased estimator of $\sigma_{x}^{2}$,

$$
s^{2}=\frac{1}{n} \sum_{i=1}^{n}\left(X_{i}-\bar{X}\right)^{2},
$$


and the mean squared difference between successive observations,

$$
d^{2}=\frac{1}{n-1} \sum_{i=1}^{n-1}\left(X_{i+1}-X_{i}\right)^{2}
$$

von Neumann (1941) examined the ratio $V=d^{2} / s^{2}$. This ratio is intuitively appealing as a measure of independence between successive observations, because $s^{2}$ represents a measure of variability that does not consider the order of observations, whereas the importance of order is explicit in $d^{2}$ (von Neumann et al. 1941). Hence, testing the null model of independence is equivalent to testing for significant differences between $d^{2}$ and $s^{2}$. Von Neumann (1941) used the normality assumption to show that $V$ and $s^{2}$ are stochastically independent random variables, so that $E(V)=$ $E\left(d^{2}\right) / E\left(s^{2}\right)=2 n /(n-1)$ under the assumption of independence, where $E$ is expected value. Thus for large $n$ (or for all $n$ if the unbiased estimator for $\sigma_{X}{ }^{2}$ is used), observed values of $V$ that are significantly less than 2 indicate positive autocorrelation or aggregation between successive observations, whereas values of $V$ significantly greater than 2 indicate overdispersion between observations.

Despite its appealing properties, von Neumann's $V$ is not directly applicable to studies of autoregressive processes in animal movements, because $V$ belongs to a univariate family of distributions, whereas bivariate or trivariate distributions are necessary to describe animal movements (Calhoun and Casby 1958, Jennrich and Turner 1969, Koeppl et al. 1975, 1977). Schoener (1981) described a bivariate extension of von Neumann's $V$ calculated from a random sample of size $n$ drawn from any bivariate distribution with means $\left(\mu_{X}\right.$, $\left.\mu_{Y}\right)$ and variances $\left(\sigma_{X}^{2}, \sigma_{Y}^{2}\right)$, respectively. In the discussion following, note that covariance of $X$ and $Y$ does not affect distances between points and so does not enter Schoener's (1981) argument. He defined the mean squared distance between successive observations as

$$
\begin{aligned}
t^{2}= & \frac{1}{m} \sum_{i=1}^{m}\left(X_{i+1}-X_{i}\right)^{2} \\
& +\frac{1}{m} \sum_{i=1}^{m}\left(Y_{i+1}-Y_{i}\right)^{2},
\end{aligned}
$$

where $m$ is the number of pairs of successive observations ( $m=n-1$ when all pairs are used) and $i$ denotes the order in which observations were collected. The mean squared distance from the center of activity $(\bar{X}, \bar{Y})$ is given by

$$
\begin{aligned}
r^{2}= & \frac{1}{n-1} \sum_{i=1}^{n}\left(X_{i}-\bar{X}\right)^{2} \\
& +\frac{1}{n-1} \sum_{i=1}^{n}\left(Y_{i}-\bar{Y}\right)^{2},
\end{aligned}
$$

where $\bar{X}=\sum X_{i} / n$ and $\bar{Y}=\sum Y_{i} / n$. Schoener's ratio is defined as $t^{2} / r^{2}$. Schoener (1981) demonstrated that
$E\left(t^{2}\right) / E\left(r^{2}\right)=2$, but this does not imply that the expectation of the test statistic, $t^{2} / r^{2}$, equals 2 (Hogg and Craig 1978). If $t^{2} / r^{2}$ and $r^{2}$ are stochastically independent, then $E\left(t^{2} / r^{2}\right)=E\left(t^{2}\right) / E\left(r^{2}\right)=2$, but to our knowledge such independence has not been proven. Hence, although Schoener's ratio is conceptually similar to von Neumann's $V$, it does not necessarily follow mathematically that $E\left(t^{2} / r^{2}\right)=2$. Our simulations do provide empirical support for this notion, however (see below).

\section{Monte Carlo Simulations: SuCCESSIVE ObSERVATIONS}

The ratio $t^{2} / r^{2}$ is potentially useful as a test of independence, but we were unable to derive its statistical distribution analytically. Therefore we explored the distribution of Schoener's ratio using Monte Carlo simulation techniques. Initially, $n$ independent pairs of random variables $(X, Y)$ were drawn from a bivariate normal distribution with mean $(0,0)$ and $\sigma_{X}{ }^{2}=\sigma_{Y}{ }^{2}=$ 1. A second set of simulations was then conducted using independent uniform random numbers in the interval $[0,1]$ to represent $X$ and $Y$ coordinates. Schoener's ratio $\left(t^{2} / r^{2}\right)$ was calculated 1000 times for a variety of sample sizes ( $n=5-16$ inclusive, $24,32,40$, and 100). Selected percentiles of the distribution were saved, and the process was repeated until 10 of these trials had been completed for each sample size. Means and standard errors of the percentile values were then computed, as well as the standard deviation and coefficients of skewness and kurtosis of the distribution of $t^{2} / r^{2}$. For both the normal and uniform cases, separate simulations were performed for a variety of eccentricities $(e=1,1.5,2,3,4,5,6$ where $e$ is the ratio of the lengths of the major and minor axes of the home range). Specifically, $\mu_{Y}=\mu_{X} e$ and $\sigma_{Y}^{2}=\sigma_{X}^{2} e^{2}$.

In our simulations the use of independent $X$ and $Y$ coordinates insures no covariance between $X$ and $Y$ $\left(\sigma_{X Y}=0\right)$. As noted earlier, squared distances between successive points and squared distances from the center of activity do not involve $\sigma_{X Y}$. However, eccentricity of the home range, which can be affected by $\sigma_{X Y}$, does influence the distribution of $t^{2} / r^{2}$ (Table 1). We have used $\sigma_{i} / \sigma_{j} \geq 1$ as our measure of eccentricity, but for $\sigma_{X Y} \neq 0$ the appropriate measure would be $\sqrt{\lambda_{1} / \lambda_{2}}$, where $\lambda_{1}$ and $\lambda_{2}$ are the eigenvalues of the variancecovariance matrix of $X$ and $Y$.

Table 1 presents critical values of the $t^{2} / r^{2}$ distribution for $4 \leq m<10$. We present critical values for relatively large $\alpha$ 's because our ultimate objective is to choose sampling intervals such that autocorrelation between successive observations is negligible. By increasing the time lag, $k$, between observations, we will eventually accept the null hypothesis of independence, and we chose $\alpha$ to lessen the probability of type II errors. Standard errors of mean percentile values ranged from 0.052 to 0.004 . In general, larger standard errors were associated with extreme percentiles and smaller standard errors with values near the median. 
TABLE 1. Empirically derived critical values of the $t^{2} / r^{2}$ distribution (where $t^{2}=$ the mean squared distance between successive observations and $r^{2}=$ the mean squared distance of observations from the center of activity), calculated using successive pairs of observations $(m)$ for $4 \leq m<10$.

\begin{tabular}{|c|c|c|c|c|c|c|c|}
\hline \multirow[b]{3}{*}{$m$} & \multirow[b]{3}{*}{$e^{*}$} & \multicolumn{3}{|c|}{ Normal } & \multicolumn{3}{|c|}{ Uniform } \\
\hline & & \multicolumn{3}{|c|}{$\alpha \dagger$} & \multicolumn{3}{|c|}{$\alpha \dagger$} \\
\hline & & .050 & .100 & .250 & .050 & .100 & .250 \\
\hline 4 & $\begin{array}{l}1.0 \\
1.5 \\
2.0 \\
3.0 \\
4.0 \\
5.0 \\
6.0\end{array}$ & $\begin{array}{l}1.084 \\
1.067 \\
1.000 \\
0.915 \\
0.887 \\
0.853 \\
0.841\end{array}$ & $\begin{array}{l}1.272 \\
1.259 \\
1.207 \\
1.143 \\
1.105 \\
1.097 \\
1.074\end{array}$ & $\begin{array}{l}1.605 \\
1.605 \\
1.577 \\
1.536 \\
1.526 \\
1.504 \\
1.499\end{array}$ & $\begin{array}{l}1.101 \\
1.066 \\
1.032 \\
0.969 \\
0.909 \\
0.872 \\
0.869\end{array}$ & $\begin{array}{l}1.288 \\
1.270 \\
1.223 \\
1.174 \\
1.129 \\
1.095 \\
1.100\end{array}$ & $\begin{array}{l}1.614 \\
1.610 \\
1.561 \\
1.537 \\
1.506 \\
1.508 \\
1.505\end{array}$ \\
\hline 5 & $\begin{array}{l}1.0 \\
1.5 \\
2.0 \\
3.0 \\
4.0 \\
5.0 \\
6.0\end{array}$ & $\begin{array}{l}1.165 \\
1.091 \\
1.052 \\
0.964 \\
0.938 \\
0.926 \\
0.926\end{array}$ & $\begin{array}{l}1.326 \\
1.284 \\
1.251 \\
1.178 \\
1.142 \\
1.132 \\
1.137\end{array}$ & $\begin{array}{l}1.640 \\
1.613 \\
1.592 \\
1.561 \\
1.516 \\
1.523 \\
1.531\end{array}$ & $\begin{array}{l}1.138 \\
1.112 \\
1.076 \\
1.006 \\
0.978 \\
0.947 \\
0.904\end{array}$ & $\begin{array}{l}1.308 \\
1.281 \\
1.253 \\
1.194 \\
1.174 \\
1.154 \\
1.110\end{array}$ & $\begin{array}{l}1.614 \\
1.600 \\
1.599 \\
1.561 \\
1.541 \\
1.535 \\
1.500\end{array}$ \\
\hline 6 & $\begin{array}{l}1.0 \\
1.5 \\
2.0 \\
3.0 \\
4.0 \\
5.0 \\
6.0\end{array}$ & $\begin{array}{l}1.216 \\
1.157 \\
1.099 \\
1.004 \\
0.983 \\
0.959 \\
0.941\end{array}$ & $\begin{array}{l}1.387 \\
1.329 \\
1.284 \\
1.219 \\
1.177 \\
1.170 \\
1.137\end{array}$ & $\begin{array}{l}1.676 \\
1.641 \\
1.619 \\
1.589 \\
1.547 \\
1.562 \\
1.538\end{array}$ & $\begin{array}{l}1.196 \\
1.181 \\
1.106 \\
1.054 \\
1.007 \\
0.992 \\
0.977\end{array}$ & $\begin{array}{l}1.375 \\
1.352 \\
1.283 \\
1.239 \\
1.193 \\
1.192 \\
1.188\end{array}$ & $\begin{array}{l}1.669 \\
1.647 \\
1.622 \\
1.586 \\
1.562 \\
1.557 \\
1.549\end{array}$ \\
\hline 7 & $\begin{array}{l}1.0 \\
1.5 \\
2.0 \\
3.0 \\
4.0 \\
5.0 \\
6.0\end{array}$ & $\begin{array}{l}1.226 \\
1.191 \\
1.143 \\
1.073 \\
1.005 \\
1.001 \\
0.980\end{array}$ & $\begin{array}{l}1.383 \\
1.368 \\
1.315 \\
1.255 \\
1.218 \\
1.199 \\
1.184\end{array}$ & $\begin{array}{l}1.665 \\
1.662 \\
1.637 \\
1.602 \\
1.569 \\
1.574 \\
1.576\end{array}$ & $\begin{array}{l}1.250 \\
1.223 \\
1.145 \\
1.093 \\
1.040 \\
1.037 \\
1.037\end{array}$ & $\begin{array}{l}1.403 \\
1.384 \\
1.322 \\
1.259 \\
1.236 \\
1.231 \\
1.226\end{array}$ & $\begin{array}{l}1.680 \\
1.670 \\
1.635 \\
1.592 \\
1.584 \\
1.570 \\
1.586\end{array}$ \\
\hline 8 & $\begin{array}{l}1.0 \\
1.5 \\
2.0 \\
3.0 \\
4.0 \\
5.0 \\
6.0\end{array}$ & $\begin{array}{l}1.257 \\
1.215 \\
1.165 \\
1.086 \\
1.050 \\
1.052 \\
1.031\end{array}$ & $\begin{array}{l}1.413 \\
1.374 \\
1.326 \\
1.271 \\
1.233 \\
1.237 \\
1.216\end{array}$ & $\begin{array}{l}1.695 \\
1.667 \\
1.643 \\
1.618 \\
1.579 \\
1.598 \\
1.583\end{array}$ & $\begin{array}{l}1.255 \\
1.217 \\
1.171 \\
1.116 \\
1.075 \\
1.079 \\
1.040\end{array}$ & $\begin{array}{l}1.403 \\
1.386 \\
1.346 \\
1.297 \\
1.266 \\
1.263 \\
1.230\end{array}$ & $\begin{array}{l}1.689 \\
1.674 \\
1.652 \\
1.623 \\
1.609 \\
1.592 \\
1.579\end{array}$ \\
\hline 9 & $\begin{array}{l}1.0 \\
1.5 \\
2.0 \\
3.0 \\
4.0 \\
5.0 \\
6.0\end{array}$ & $\begin{array}{l}1.301 \\
1.269 \\
1.194 \\
1.138 \\
1.086 \\
1.071 \\
1.072\end{array}$ & $\begin{array}{l}1.452 \\
1.420 \\
1.370 \\
1.319 \\
1.282 \\
1.265 \\
1.271\end{array}$ & $\begin{array}{l}1.707 \\
1.689 \\
1.672 \\
1.646 \\
1.623 \\
1.612 \\
1.611\end{array}$ & $\begin{array}{l}1.299 \\
1.262 \\
1.214 \\
1.165 \\
1.121 \\
1.091 \\
1.085\end{array}$ & $\begin{array}{l}1.448 \\
1.425 \\
1.371 \\
1.333 \\
1.308 \\
1.283 \\
1.281\end{array}$ & $\begin{array}{l}1.705 \\
1.686 \\
1.673 \\
1.638 \\
1.624 \\
1.613 \\
1.603\end{array}$ \\
\hline
\end{tabular}

* $e=$ eccentricity, the ratio of the lengths of the major and minor axes of the home range.

$\dagger$ Significance levels $(\alpha)$ are appropriate for one-tailed tests of the null hypothesis: $t^{2} / r^{2} \geq 2$.

Comparison of coefficients of skewness and kurtosis and percentile values $( \pm 2 \mathrm{SE})$ indicated that, for sample sizes of 10 or more, the empirical distribution of Schoener's ratio closely approximated a normal distribution with mean 2 , regardless of the kurtosis of the distribution of $(X, Y)$ pairs or the eccentricity of the home range. Thus, knowledge of $s$, the sample standard deviation of $t^{2} / r^{2}$, would permit simple calculation of critical values using a standard normal table. Graphical analysis (Fig. 1) suggested that $\ln m$ and $e$ might be useful predictors of $s$; examination of residuals suggested the quadratic term $e^{2}$ was also important. Thus, we fitted multiple regression models (with $\ln s$ as the dependent variable) for the $t^{2} / r^{2}$ distributions derived from bivariate uniform and bivariate normal random variables using $e, e^{2}$, and $\ln m(m \geq 7)$ as predictor variables. Both regression equations fit the model extremely well $\left(R^{2}=0.995\right.$ for uniform, $R^{2}=0.997$ for normal), and no pattern could be discerned in the standardized residuals. The equations for uniform and normal cases, respectively, are:

$$
\begin{aligned}
\ln s= & -0.0751+0.173(e)-0.0164\left(e^{2}\right) \\
& -0.433(\ln m) \\
\ln s= & -0.0502+0.164(e)-0.0156\left(e^{2}\right) \\
& -0.437(\ln m) .
\end{aligned}
$$

Approximate tests of significance of the regression coef- 


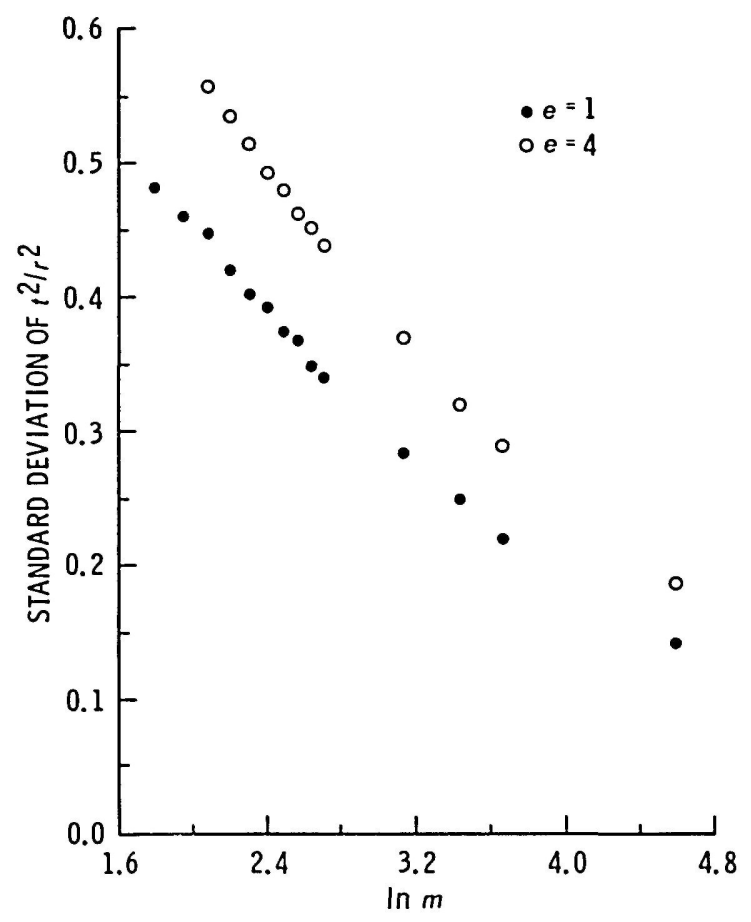

FIG. 1. Graphical depiction of the relationship between sample size $m$ (number of pairs of observations), eccentricity $e$ (the ratio of the lengths of the major and minor home-range axes), and the sample standard deviation of the $t^{2} / r^{2}$ distribution, normal case. $t^{2}=$ mean squared distance between successive observations. $r^{2}=$ mean squared distance of observations from the center of activity. For illustrative purposes, only standard deviations from distributions with eccentricities of 1 and 4 are shown. Sample sizes were included in the plot cinly if the corresponding $t^{2} / r^{2}$ distribution was normally distributed.

ficients revealed no differences between corresponding coefficients of the equations for uniform and normal distributions $(P>.10$ in all four instances), which suggests that for $m>9$, different sampling distributions yield nearly equivalent normal representations for the $t^{2} / r^{2}$ distribution.

\section{TESTING FOR INDEPENDENCE: AN EXAMPLE}

To illustrate the use of Schoener's ratio as a test of the null hypothesis of independence, we radio-tracked a 125-g resident female cotton rat (Sigmodon hispidus) from 17 to 22 December 1982 in an old pasture on the John H. Nelson Environmental Studies Area, 14 $\mathrm{km}$ northeast of Lawrence, Kansas. The cotton rat was equipped with a 3.2-g transmitter package on 15 December and held for nearly $48 \mathrm{~h}$ for observation. She was then released at the point of capture. Tracking was conducted from 1200 to 2000 each day with a handheld three-element Yagi antenna. We attempted to make locational readings by triangulation at 5 -min intervals, but 10 -min intervals were common also. The locational records were consistent with previous trapping
TABLE 2. A comparison of critical values of $t^{2} / r^{2}$ distributions derived from uniform (U), normal $(\mathrm{N})$, and observed (O) sampling distributions for successive observations. Estimated eccentricity $\hat{\boldsymbol{e}}=1.61$. Symbols defined in Table 1 .

\begin{tabular}{ccccc}
\hline \hline $\begin{array}{c}\text { Sampling } \\
\text { distri- } \\
\text { bution }\end{array}$ & $m$ & \multicolumn{3}{c}{$\alpha$} \\
\cline { 3 - 5 } \cline { 3 - 5 } & & .050 & .100 & .250 \\
\hline $\mathrm{U}$ & 40 & 1.609 & 1.695 & 1.839 \\
$\mathrm{~N}$ & 1.610 & 1.696 & 1.840 \\
$\mathrm{O}$ & & 1.596 & 1.683 & 1.833 \\
$\mathrm{U}$ & & 1.737 & 1.795 & 1.892 \\
$\mathrm{~N}$ & 100 & 1.738 & 1.796 & 1.893 \\
$\mathrm{O}$ & & 1.744 & 1.801 & 1.895 \\
$\mathrm{U}$ & & 1.805 & 1.848 & 1.920 \\
$\mathrm{~N}$ & 200 & 1.807 & 1.849 & 1.921 \\
$\mathrm{O}$ & & 1.817 & 1.856 & 1.921 \\
\hline
\end{tabular}

records, and the radio collar appeared to have no adverse effect on the cotton rat; her body mass was $127 \mathrm{~g}$ at the conclusion of the study.

The observed distribution of locational records resulting from the telemetry study was multimodal and asymmetric (Fig. 2) and clearly did not conform to either of the sampling distributions employed in our simulations (bivariate uniform, bivariate normal). Indeed, animal movements in general may arise from strange sampling distributions more frequently than they arise from common, well-known distributions (e.g., Adams and Davis 1967, Schoener 1981, Anderson 1982; but see Hawes 1977). If this supposition is true, then the utility of the critical values of $t^{2} / r^{2}$ that we have provided (Table 1; Eqs. 5 and 6 ) depends on the impact the underlying sampling distributions of $X$ and $Y$ have on the distribution of $t^{2} / r^{2}$.

To check the generality of the $t^{2} / r^{2}$ distribution, we performed the following randomization experiment. Sampling with replacement, random samples of loca-

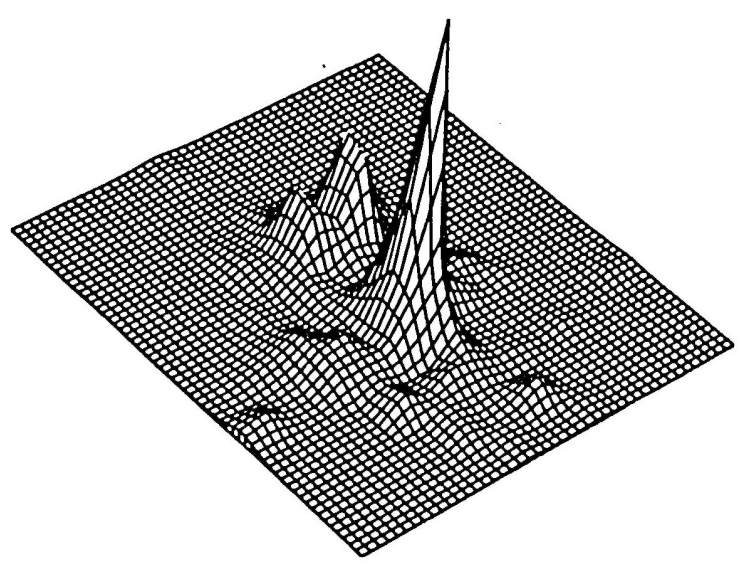

Fig. 2. Distribution of locational records for a radio-collared adult female cotton rat near Lawrence, Kansas, from 17 to 22 December 1982. The large peak in the utilization distribution occurred at a $15-\mathrm{m}^{2}$ brush pile, presumably the female's nesting site. Each grid square represents $\approx 3.8 \mathrm{~m}^{2}$. 
TABLE 3. Empirically derived critical values of the $t^{2} / r^{2}$ distribution calculated using disjunct pairs of observations $(m)$ for $4 \leq m<15$. Symbols defined in Table 1 .

\begin{tabular}{|c|c|c|c|c|c|c|c|}
\hline \multirow[b]{3}{*}{$m$} & \multirow[b]{3}{*}{$e^{*}$} & \multicolumn{3}{|c|}{ Normal } & \multicolumn{3}{|c|}{ Uniform } \\
\hline & & \multicolumn{3}{|c|}{$\alpha \dagger$} & \multicolumn{3}{|c|}{$\alpha \dagger$} \\
\hline & & .050 & .100 & .250 & .050 & .100 & .250 \\
\hline 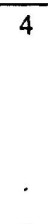 & $\begin{array}{l}1.0 \\
1.5 \\
2.0 \\
3.0 \\
4.0 \\
5.0 \\
6.0\end{array}$ & $\begin{array}{l}0.902 \\
0.864 \\
0.800 \\
0.660 \\
0.594 \\
0.583 \\
0.534\end{array}$ & $\begin{array}{l}1.140 \\
1.094 \\
1.013 \\
0.910 \\
0.863 \\
0.834 \\
0.818\end{array}$ & $\begin{array}{l}1.557 \\
1.541 \\
1.479 \\
1.428 \\
1.405 \\
1.377 \\
1.385\end{array}$ & $\begin{array}{l}0.968 \\
0.917 \\
0.869 \\
0.755 \\
0.686 \\
0.636 \\
0.640\end{array}$ & $\begin{array}{l}1.187 \\
1.126 \\
1.094 \\
0.991 \\
0.917 \\
0.898 \\
0.889\end{array}$ & $\begin{array}{l}1.577 \\
1.542 \\
1.538 \\
1.473 \\
1.417 \\
1.411 \\
1.396\end{array}$ \\
\hline 5 & $\begin{array}{l}1.0 \\
1.5 \\
2.0 \\
3.0 \\
4.0 \\
5.0 \\
6.0\end{array}$ & $\begin{array}{l}1.008 \\
0.948 \\
0.858 \\
0.776 \\
0.710 \\
0.690 \\
0.673\end{array}$ & $\begin{array}{l}1.218 \\
1.161 \\
1.093 \\
1.014 \\
0.952 \\
0.929 \\
0.927\end{array}$ & $\begin{array}{l}1.585 \\
1.565 \\
1.521 \\
1.491 \\
1.454 \\
1.410 \\
1.439\end{array}$ & $\begin{array}{l}1.028 \\
0.989 \\
0.917 \\
0.844 \\
0.789 \\
0.767 \\
0.734\end{array}$ & $\begin{array}{l}1.220 \\
1.213 \\
1.126 \\
1.073 \\
1.020 \\
1.006 \\
0.973\end{array}$ & $\begin{array}{l}1.584 \\
1.580 \\
1.536 \\
1.503 \\
1.483 \\
1.461 \\
1.450\end{array}$ \\
\hline 6 & $\begin{array}{l}1.0 \\
1.5 \\
2.0 \\
3.0 \\
4.0 \\
5.0 \\
6.0\end{array}$ & $\begin{array}{l}1.099 \\
1.031 \\
0.945 \\
0.871 \\
0.800 \\
0.753 \\
0.753\end{array}$ & $\begin{array}{l}1.283 \\
1.227 \\
1.158 \\
1.093 \\
1.029 \\
0.992 \\
1.001\end{array}$ & $\begin{array}{l}1.623 \\
1.596 \\
1.562 \\
1.517 \\
1.475 \\
1.465 \\
1.468\end{array}$ & $\begin{array}{l}1.104 \\
1.052 \\
0.997 \\
0.888 \\
0.847 \\
0.843 \\
0.829\end{array}$ & $\begin{array}{l}1.289 \\
1.246 \\
1.190 \\
1.114 \\
1.070 \\
1.071 \\
1.061\end{array}$ & $\begin{array}{l}1.635 \\
1.604 \\
1.560 \\
1.512 \\
1.514 \\
1.510 \\
1.489\end{array}$ \\
\hline 7 & $\begin{array}{l}1.0 \\
1.5 \\
2.0 \\
3.0 \\
4.0 \\
5.0 \\
6.0\end{array}$ & $\begin{array}{l}1.138 \\
1.110 \\
1.020 \\
0.913 \\
0.874 \\
0.846 \\
0.858\end{array}$ & $\begin{array}{l}1.324 \\
1.291 \\
1.216 \\
1.138 \\
1.101 \\
1.085 \\
1.094\end{array}$ & $\begin{array}{l}1.639 \\
1.617 \\
1.579 \\
1.546 \\
1.513 \\
1.519 \\
1.517\end{array}$ & $\begin{array}{l}1.151 \\
1.126 \\
1.073 \\
0.963 \\
0.913 \\
0.922 \\
0.811\end{array}$ & $\begin{array}{l}1.338 \\
1.308 \\
1.270 \\
1.176 \\
1.129 \\
1.135 \\
1.109\end{array}$ & $\begin{array}{l}1.648 \\
1.635 \\
1.601 \\
1.563 \\
1.523 \\
1.538 \\
1.519\end{array}$ \\
\hline 8 & $\begin{array}{l}1.0 \\
1.5 \\
2.0 \\
3.0 \\
4.0 \\
5.0 \\
6.0\end{array}$ & $\begin{array}{l}1.209 \\
1.159 \\
1.078 \\
0.983 \\
0.945 \\
0.927 \\
0.916\end{array}$ & $\begin{array}{l}1.373 \\
1.340 \\
1.265 \\
1.188 \\
1.166 \\
1.139 \\
1.147\end{array}$ & $\begin{array}{l}1.669 \\
1.648 \\
1.613 \\
1.572 \\
1.560 \\
1.536 \\
1.539\end{array}$ & $\begin{array}{l}1.214 \\
1.177 \\
1.108 \\
1.034 \\
0.976 \\
0.976 \\
0.969\end{array}$ & $\begin{array}{l}1.382 \\
1.354 \\
1.305 \\
1.220 \\
1.190 \\
1.167 \\
1.176\end{array}$ & $\begin{array}{l}1.664 \\
1.653 \\
1.629 \\
1.588 \\
1.566 \\
1.559 \\
1.543\end{array}$ \\
\hline 9 & $\begin{array}{l}1.0 \\
1.5 \\
2.0 \\
3.0 \\
4.0 \\
5.0 \\
6.0\end{array}$ & $\begin{array}{l}1.261 \\
1.184 \\
1.138 \\
1.034 \\
0.997 \\
0.977 \\
0.969\end{array}$ & $\begin{array}{l}1.418 \\
1.361 \\
1.315 \\
1.238 \\
1.209 \\
1.184 \\
1.180\end{array}$ & $\begin{array}{l}1.688 \\
1.666 \\
1.634 \\
1.596 \\
1.576 \\
1.567 \\
1.564\end{array}$ & $\begin{array}{l}1.263 \\
1.210 \\
1.153 \\
1.091 \\
1.046 \\
1.014 \\
0.998\end{array}$ & $\begin{array}{l}1.422 \\
1.378 \\
1.333 \\
1.283 \\
1.230 \\
1.203 \\
1.204\end{array}$ & $\begin{array}{l}1.690 \\
1.665 \\
1.645 \\
1.612 \\
1.583 \\
1.566 \\
1.575\end{array}$ \\
\hline 10 & $\begin{array}{l}1.0 \\
1.5 \\
2.0 \\
3.0 \\
4.0 \\
5.0 \\
6.0\end{array}$ & $\begin{array}{l}1.286 \\
1.229 \\
1.171 \\
1.103 \\
1.053 \\
1.041 \\
1.017\end{array}$ & $\begin{array}{l}1.440 \\
1.397 \\
1.346 \\
1.297 \\
1.253 \\
1.251 \\
1.225\end{array}$ & $\begin{array}{l}1.706 \\
1.689 \\
1.650 \\
1.619 \\
1.597 \\
1.598 \\
1.587\end{array}$ & $\begin{array}{l}1.275 \\
1.240 \\
1.198 \\
1.118 \\
1.087 \\
1.069 \\
1.038\end{array}$ & $\begin{array}{l}1.428 \\
1.406 \\
1.364 \\
1.293 \\
1.268 \\
1.262 \\
1.239\end{array}$ & $\begin{array}{l}1.697 \\
1.679 \\
1.659 \\
1.611 \\
1.626 \\
1.609 \\
1.587\end{array}$ \\
\hline 11 & $\begin{array}{l}1.0 \\
1.5 \\
2.0 \\
3.0 \\
4.0 \\
5.0 \\
6.0\end{array}$ & $\begin{array}{l}1.320 \\
1.266 \\
1.195 \\
1.117 \\
1.083 \\
1.084 \\
1.066\end{array}$ & $\begin{array}{l}1.469 \\
1.421 \\
1.364 \\
1.303 \\
1.268 \\
1.286 \\
1.250\end{array}$ & $\begin{array}{l}1.721 \\
1.685 \\
1.667 \\
1.618 \\
1.615 \\
1.618 \\
1.603\end{array}$ & $\begin{array}{l}1.334 \\
1.274 \\
1.230 \\
1.156 \\
1.130 \\
1.102 \\
1.095\end{array}$ & $\begin{array}{l}1.480 \\
1.428 \\
1.384 \\
1.334 \\
1.304 \\
1.280 \\
1.285\end{array}$ & $\begin{array}{l}1.720 \\
1.697 \\
1.673 \\
1.637 \\
1.616 \\
1.605 \\
1.615\end{array}$ \\
\hline 12 & $\begin{array}{l}1.0 \\
1.5 \\
2.0 \\
3.0 \\
4.0 \\
5.0 \\
6.0\end{array}$ & $\begin{array}{l}1.345 \\
1.304 \\
1.242 \\
1.184 \\
1.132 \\
1.125 \\
1.092\end{array}$ & $\begin{array}{l}1.491 \\
1.454 \\
1.405 \\
1.349 \\
1.327 \\
1.297 \\
1.273\end{array}$ & $\begin{array}{l}1.728 \\
1.706 \\
1.684 \\
1.662 \\
1.653 \\
1.625 \\
1.625\end{array}$ & $\begin{array}{l}1.337 \\
1.311 \\
1.263 \\
1.158 \\
1.169 \\
1.130 \\
1.127\end{array}$ & $\begin{array}{l}1.474 \\
1.455 \\
1.414 \\
1.343 \\
1.336 \\
1.311 \\
1.317\end{array}$ & $\begin{array}{l}1.719 \\
1.712 \\
1.687 \\
1.636 \\
1.648 \\
1.631 \\
1.625\end{array}$ \\
\hline
\end{tabular}


Table 3. Continued.

\begin{tabular}{|c|c|c|c|c|c|c|c|}
\hline \multirow[b]{3}{*}{$m$} & \multirow[b]{3}{*}{$e^{*}$} & \multicolumn{3}{|c|}{ Normal } & \multicolumn{3}{|c|}{ Uniform } \\
\hline & & \multicolumn{3}{|c|}{$\alpha \dagger$} & \multicolumn{3}{|c|}{$\alpha \dagger$} \\
\hline & & .050 & .100 & .250 & .050 & .100 & .250 \\
\hline 13 & $\begin{array}{l}1.0 \\
1.5 \\
2.0 \\
3.0 \\
4.0 \\
5.0 \\
6.0\end{array}$ & $\begin{array}{l}1.364 \\
1.323 \\
1.273 \\
1.187 \\
1.183 \\
1.151 \\
1.151\end{array}$ & $\begin{array}{l}1.503 \\
1.464 \\
1.433 \\
1.359 \\
1.358 \\
1.327 \\
1.316\end{array}$ & $\begin{array}{l}1.738 \\
1.722 \\
1.690 \\
1.668 \\
1.657 \\
1.646 \\
1.634\end{array}$ & $\begin{array}{l}1.377 \\
1.321 \\
1.266 \\
1.201 \\
1.166 \\
1.182 \\
1.144\end{array}$ & $\begin{array}{l}1.507 \\
1.468 \\
1.429 \\
1.375 \\
1.341 \\
1.350 \\
1.322\end{array}$ & $\begin{array}{l}1.740 \\
1.710 \\
1.701 \\
1.669 \\
1.651 \\
1.645 \\
1.633\end{array}$ \\
\hline 14 & $\begin{array}{l}1.0 \\
1.5 \\
2.0 \\
3.0 \\
4.0 \\
5.0 \\
6.0\end{array}$ & $\begin{array}{l}1.391 \\
1.347 \\
1.287 \\
1.224 \\
1.209 \\
1.170 \\
1.166\end{array}$ & $\begin{array}{l}1.526 \\
1.489 \\
1.445 \\
1.385 \\
1.375 \\
1.354 \\
1.342\end{array}$ & $\begin{array}{l}1.752 \\
1.730 \\
1.700 \\
1.673 \\
1.679 \\
1.655 \\
1.639\end{array}$ & $\begin{array}{l}1.403 \\
1.357 \\
1.318 \\
1.246 \\
1.210 \\
1.187 \\
1.190\end{array}$ & $\begin{array}{l}1.526 \\
1.493 \\
1.464 \\
1.403 \\
1.374 \\
1.362 \\
1.356\end{array}$ & $\begin{array}{l}1.749 \\
1.727 \\
1.715 \\
1.680 \\
1.665 \\
1.652 \\
1.664\end{array}$ \\
\hline
\end{tabular}

${ }^{*} e=$ eccentricity, the ratio of the lengths of the major and minor axes of the home range.

$\dagger$ Significance levels $(\alpha)$ are appropriate for one-tailed tests of the null hypothesis: $t^{2} / r^{2} \geq 2$.

tional observations ( $m=40,100,200)$ were drawn from the observed cotton rat data, resulting in $m$ independent pairs of values $(X, Y)$ that were distributed approximately as the distribution depicted in Fig. 2. Simulations were conducted for each sample size as described above in Monte Carlo Simulations: Successive Observations, producing critical values of $t^{2} / r^{2}$ from this unusual sampling distribution (Fig. 2).

To compare critical values of $t^{2} / r^{2}$ generated via the randomization experiment with critical values obtained from Eqs. 5 and 6, we estimated the eccentricity of the cotton rat's home range using $\hat{e}=\sqrt{\lambda_{1} / \lambda_{2}}$. In this case $\hat{e}=1.61$. Critical values derived from the true sampling distribution were nearly identical with those derived from bivariate normal and bivariate uniform sampling distributions (Table 2).

T. W. Schoener (personal communication) suggested that we conduct an additional test of the generality of the distribution of $t^{2} / r^{2}$ by selecting random points from a "funnel-shaped distribution." We did this by selecting bivariate observations from a circular (or elliptical) beta distribution with parameters $V=2$ and $W=1$ (cf. Hastings and Peacock 1975). In a cross section through the mean, the probability distribution resembles a " $V$," with highest probability of occurrence at the home range boundary and a linear decrease to zero at the center. Simulations for eccentricities of 1.0, 1.5 , and 2.0 produced $t^{2} / r^{2}$ distributions that were not significantly different from the normal or uniform results.

Thus, it appears that for reasonable sample sizes, the $t^{2} / r^{2}$ distribution is not affected by the underlying distribution of $X$ and $Y$. Although small values of $m$ may weaken the robustness of $t^{2} / r^{2}$, we point out that small $m$ also restricts one's ability to estimate the underlying distribution of $X$ and $Y$. Thus, if $m$ is small either an assumption must be made regarding the sampling distribution or a randomization experiment must be con- ducted to produce critical values of $t^{2} / r^{2}$ derived from the empirical sampling distribution (but see Schoener 1981 for an alternative approach).

Using Eqs. 3 and 4, we calculated $t^{2}$ and $r^{2}$ for the cotton rat with all 302 successive pairs of observations. The resulting $t^{2} / r^{2}$ value was 0.499 . The estimated standard deviation of $t^{2} / r^{2}$ was calculated from both Eqs. 5 and 6 as $s=0.0956$. Because we were interested in the alternative hypothesis of positive association between successive observations, we tested the null hypothesis that observations were independent or overdispersed (i.e., $t^{2} / r^{2} \geq 2$ ). The $\alpha=.25$ critical value for this one-tailed test was $2-(0.675 \times 0.0956)=$ 1.935 , where 2 is the mean of $t^{2} / r^{2}$ and 0.675 represents the 75 th percentile of the standard normal distribution. Because 1.935 is greater than 0.499 , we concluded that successive observations were positively correlated.

\section{Monte Carlo Simulations: NonConsecutive ObSERVATIONS}

If successive observations are independent, then all locational records, irrespective of time lags between observations, may be used in statistical procedures for computing home range size. Dependence between successive observations for an individual with a stable home range, however, implies that the time interval, $k$, separating these observations is too short to meet the statistical assumption of independence. By calculating Schoener's $t^{2} / r^{2}$ for records separated by various time intervals, a subset of observations may eventually be selected for which the independence assumption is reasonable. Further, the time lag at which autocorrelation can be ignored can be estimated with this procedure. This latter point may be especially helpful in pilot studies geared toward determining optimal sampling effort.

If all successive observations are equally spaced in time, tests of $t^{2} / r^{2}$ values calculated from nonconsec- 
TABLE 4. A comparison of critical values of $t^{2} / r^{2}$ distributions derived from uniform $(\mathrm{U})$, normal $(\mathrm{N})$, and observed (O) sampling distributions for disjunct pairs of observations. Estimated eccentricity $\hat{e}=1.61$. Symbols defined in Table 1.

\begin{tabular}{ccccc}
\hline \hline Sampling & & \multicolumn{3}{c}{$\alpha$} \\
\cline { 3 - 5 } $\begin{array}{c}\text { distri- } \\
\text { bution }\end{array}$ & $m$ & .050 & .100 & .250 \\
\hline $\mathrm{U}$ & & 1.603 & 1.690 & 1.837 \\
$\mathrm{~N}$ & 40 & 1.604 & 1.692 & 1.838 \\
$\mathrm{O}$ & & 1.600 & 1.684 & 1.833 \\
$\mathrm{U}$ & & 1.744 & 1.801 & 1.895 \\
$\mathrm{~N}$ & 100 & 1.743 & 1.800 & 1.894 \\
$\mathrm{O}$ & & 1.745 & 1.803 & 1.893 \\
$\mathrm{U}$ & & 1.817 & 1.857 & 1.925 \\
$\mathrm{~N}$ & 200 & 1.815 & 1.856 & 1.924 \\
$\mathrm{O}$ & & 1.818 & 1.859 & 1.927 \\
\hline
\end{tabular}

utive locational records $(k>1)$ may be performed as in the example above, using all possible pairs of observations for $t^{2}(m=n-k)$ and all $n$ observations for $r^{2}$. However, such a data set probably is the exception rather than the rule because many problems may arise in taking a locational reading at a specified time (e.g., radio interference or power failure with telemetry, loss of visual contact with direct observation). Gaps in the time series of locational records mean that $m$, the number of pairs, may not simply be $k$ less than the number of observations, and that some observations cannot be used with a particular $k$ even though they are in the middle of a data series. This could alter the distribution of $t^{2} / r^{2}$ (see Eqs. 3 and 4).

To test for the effect of gaps in the data, we examined the most extreme case of discontinuous observations, the case in which each record occurs in only one pair of observations separated by $k$ units. That is, $t^{2}$ is still the squared distance between the $i^{\text {th }}$ and $(i+1)^{\text {th }}$ observations, but $i$ is allowed to take on odd values only; thus each observation is used only once in the calculation of $t^{2}$. In this disjunct case, $m=n / 2$. Using the simulation procedure described earlier, we again derived $t^{2} / r^{2}$ distributions with independent random variables drawn from bivariate normal and bivariate uniform sampling distributions. In each simulation, $m=4-16,24,32,40$, and 100 disjunct pairs of points were used, and simulations were conducted for eccentricities of $1,1.5,2,3,4,5$, and 6 .

Standard errors of mean percentile values ranged from 0.054 to 0.004 and exhibited the same trends as in the simulations for successive points. In addition, all $t^{2} / r^{2}$ distributions generated with at least 15 pairs of points converged to normality (with mean 2 ) for the disjunct case (Table 3). To permit use of standard normal tables when $m \geq 15$, multiple regression equations were fitted to the data as outlined previously. Once again, the model fit was very good $\left(R^{2}=0.998\right.$ for both uniform and normal). The equations for the uniform and normal disjunct cases are:

$$
\begin{aligned}
\ln s= & 0.1014+0.185(e)-0.0179\left(e^{2}\right) \\
& -0.481(\ln m) \\
\ln s= & 0.0679+0.179(e)-0.0169\left(e^{2}\right) \\
& -0.471(\ln m) .
\end{aligned}
$$

Approximate significance tests revealed that the intercepts and the coefficients of $e^{2}$ differed $(P \leqslant .05)$ between these equations. Further, regression coefficients from the simulations of disjunct pairs differed $(P \leqslant$ .05 ) from coefficients associated with simulations of successive pairs (Eqs. 5 and 6), indicating that $t^{2} / r^{2}$ ratios in the disjunct case follow normal distributions with variances different from those in the successive case.

Unlike the case of successive pairs, the $t^{2} / r^{2}$ distribution from disjunct data varies somewhat with the distribution of $X$ and $Y$. Eqs. 7 and 8 may be used to calculate critical values for $t^{2} / r^{2}$ but need not give comparable results. Fortunately, Eqs. 7 and 8 appear to yield equivalent critical values for $30 \leq m \leq 200$ and $1 \leq e \leq 5$. The estimates of $s$ from Eqs. 7 and 8 are within 0.0014 for $e=1.5$ and $35 \leq m \leq 200$, the range of data in our example problem.

Results of randomization experiments for disjunct pairs of observations ( $m=40,100,200)$ drawn from the cotton rat data indicated close agreement between critical values derived from the empirical sampling distributions and those obtained from simulations using the bivariate uniform or bivariate normal distributions (Table 4). In addition, simulations using the funnel-shaped beta distribution yielded $t^{2} / r^{2}$ distributions that were statistically indistinguishable from the normal or uniform results.

Because most sampling schemes will fall between the extremes of continuity and discontinuity in data collection, we suggest that critical values obtained from Tables 1 and 3 (or from the appropriate equations if $m$ is large) be used as lower and upper bounds of significance (after Durbin and Watson 1971). For example, if $m=8$, then a one-tailed test of independence (i.e., $\mathrm{H}_{0}: t^{2} / r^{2} \geq 2$ ) may proceed as follows. For convenience, assume that the distribution of activity is bivariate uniform and that the home range exhibits an eccentricity of one. At the $\alpha=.25$ level, the critical value from Table 1 is 1.689 , and the critical value from Table 3 is 1.664 . The testing criteria are: (1) if the observed $t^{2} / r^{2}$ is greater than the upper bound (1.689), do not reject $\mathrm{H}_{0}$; (2) if the observed $t^{2} / r^{2}$ is less than the lower bound (1.664), reject $\mathrm{H}_{0}$ in favor of the hypothesis of dependence; (3) if $t^{2} / r^{2}$ falls between the upper and lower bounds and the data collection interval is irregular, the test is indeterminate.

\section{DETERMINING THE "TIME TO INDEPENDENCE"}

Because successive observations of the cotton rat were dependent, we asked the following question: what is the minimal time interval necessary to yield "independent" pairs of observations? To answer this ques- 


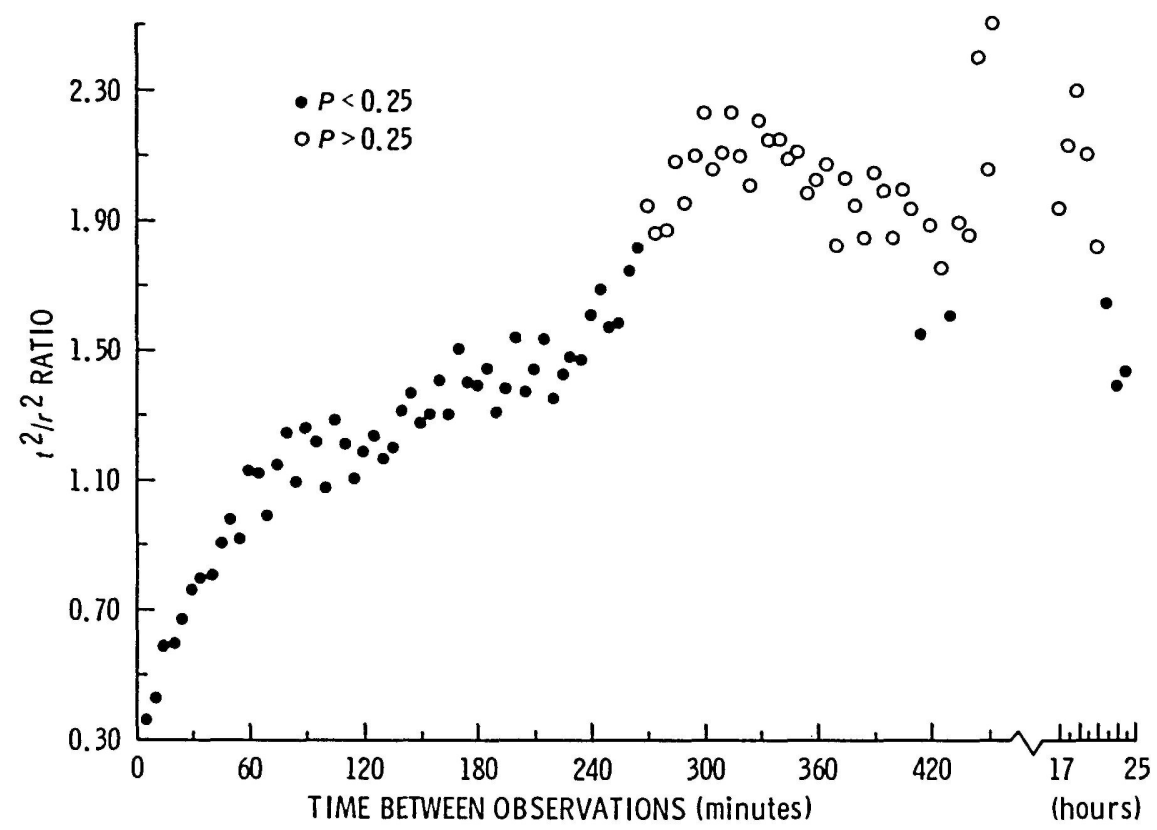

FIG. 3. Vaiues of Schoener's (1981) $t^{2} / r^{2}$ ratio as a function of the time interval between observations; $t^{2}$ and $r^{2}$ are defined in the Table $!$ legend. Significance tests of each ratio were conducted using Eqs. 5-8.

tion, $t^{2} / r^{2}$ vatues were calculated for all locational records separated by a specified time lag, $k$, where $k$ ranged from 5 to $455 \mathrm{~min}$ in 5 -min increments. Schoener's ratio was also calculated for $k=17,18, \ldots$, and $24 \mathrm{~h}$.

Values of $t \% r^{2}$ increased steadily from $k=5 \mathrm{~min}$ to $k=60 \mathrm{mir}$. then more erratically to a maximum of 2.50 at $k=45.5 \mathrm{~min}$ (Fig. 3). Interestingly, $t^{2} / r^{2}$ values declined precipitously for $k>19 \mathrm{~h}$, indicating that a diel cycle mily underlie the movements exhibited by this individual. Indeed, $35 \%$ of all points separated by $k=24 \mathrm{~h}$ were $<10 \mathrm{~m}$ apart, and most of these pairs of points $(85 \%)$ were located outside of a brush pile that served as the focal point of the cotton rat's home range (Fig. 2).

To determine the time lag at which autocorrelation was negligible, the following arbitrary but objective criterion was used. The time interval necessary to achieve independence between successive observations, $\Delta T_{l}$, was defined as the smallest $k$ exhibiting a nonsignificant ( $\alpha=.25$, one-tailed test) $t^{2} / r^{2}$ ratio and followed consecutively by at least two $k$ values with nonsignificant $t^{2} / r^{2}$ ratios. Using this criterion, independence was achieved at a time interval of $270 \mathrm{~min}$ for the female cotton rat (Fig. 3). Following the same procedure for $\alpha=.05$ would have changed the $\Delta T_{I}$ value to $260 \mathrm{~min} . \Delta T_{I}$ also was relatively insensitive to sampling interval; using only observations separated by at least $30 \mathrm{~min}$ resulted in a $\Delta T_{I}$ of $270 \mathrm{~min}$.

We believe that the measure $\Delta T_{I}$ may prove very useful in comparing seasonal or interspecific differences in the time scaling of movements, because Schoener's ratio is a dimensionless number, hence $\Delta T_{I}$ is not influenced by home range size. One potential application might be in testing Mitani and Rodman's (1979) hypothesis that a proximate determinant of territoriality in primates is the ability of a troop to travel across its home range in a single day. In accordance with this hypothesis, we predict that $\Delta T_{1}$ will be $<24 \mathrm{~h}$ for territorial primates and $>24 \mathrm{~h}$ for nonterritorial primates.

More generally, Lindstedt and Calder (1981) and Calder (1983) have suggested that the allometric relation between home range size and body mass of mammalian herbivores may in part be explained by physiological time scaling of space use. They predict that large herbivores use a smaller fraction of their home range in a given unit of time than do small herbivores. The "time to independence," $\Delta T_{1}$, may be thought of as the time necessary for an animal to traverse its home range; hence, $\Delta T_{I}$ is related to an animal's rate of space use and could provide a means of testing Lindstedt and Calder's (1981) assertion that time scaling influences home range size. If their assertion is correct, we expect $\Delta T_{1}$ to scale with body mass raised to the $(b-0.75)$ power, where $b$ is the scaling exponent for the home range-body mass relationship and 0.75 represents the metabolic rate-body mass scaling factor (Kleiber 1975).

Rejection of the independence hypothesis using all successive observations might occur in at least three instances, even if the time interval between observations is otherwise adequate. In the first instance, an animal that shifts its home range to a new location may have a calculated center of activity between its old and new centers of activity. This in turn would inflate the 
value of $r^{2}$ (Eq. 4), resulting in a $t^{2} / r^{2}$ value significantly less than 2. Secondly, rejection of the independence hypothesis might arise in individuals that travel along well-defined paths in a temporally predictable manner. Traplining species such as euglossine bees (Janzen 1971) and bumble bees (Manning 1956, Heinrich 1976, Pyke 1978) provide examples of this. In traplining species, plots of $t^{2} / r^{2}$ vs. time between successive observations should oscillate from low values of $t^{2} / r^{2}$ (when $k$ corresponds to relatively short distances between observations) to higher values of $t^{2} / r^{2}$ (when $k$ corresponds to longer distances). Finally, small $t^{2} / r^{2}$ values might arise if the time interval between observations corresponds to some multiple of the period length in animals displaying temporal cycles in their movements. For example, a lag of $k=24 \mathrm{~h}$ in the current study would have resulted in a $t^{2} / r^{2}$ value of 1.43 for successive observations (Fig. 3).

By presenting a means of testing for independence between successive observations, we do not intend to discourage frequent monitoring of individuals; we only suggest that the $t^{2} / r^{2}$ test enables ecologists to successfully confront this previously elusive assumption in spatial analysis.

\section{ACKNOWLEDGMENTS}

Special thanks are extended to K. B. Armitage, K. Cogger, R. D. Holt, D. H. Johnson, and T. W. Schoener for insightful comments and constructive criticism delivered during preparation of the manuscript. We also wish to express our gratitude to G. E. Glass, J. R. Sauer, B. J. Bergstrom, and J. H. Honacki for assistance with various aspects of the telemetry study. The Academic Computer Center, University of Kansas, provided computer time. Financial support was provided by a University of Kansas Honors Fellowship to R. K. Swihart and by General Research Grant 3387-0038 to N. A. Slade.

\section{Literature Cited}

Adams, L., and S. D. Davis. 1967. The internal anatomy of home range. Journal of Mammalogy 48:529-536.

Anderson, D. J. 1982. The home range: a new nonparametric estimation technique. Ecology 63:103-112.

Bulmer, M. G. 1975. The statistical analysis of density dependence. Biometrics 31:901-911.

Calder, W. A., III. 1983. Ecological scaling: mammals and birds. Annual Review of Ecology and Systematics 14:213230.

Calhoun, J. B., and J. U. Casby. 1958. Calculation of home range and density of small mammals. Public Health Monograph 55.

Chatterjee, S., and B. Price. 1977. Regression analysis by example. John Wiley and Sons, New York, New York, USA.

Don, B. A. C., and K. Rennolls. 1983. A home range model incorporating biological attraction points. Journal of Animal Ecology 52:69-81.
Dunn, J. E., and P. S. Gipson. 1977. Analysis of radio telemetry data in studies of home range. Biometrics 33:85101.

Durbin, J., and G. S. Watson. 1971. Testing for serial correlation in least squares regression. III. Biometrika 58:119.

Hastings, N. A. J., and J. B. Peacock. 1975. Statistical distributions. Butterworth, London, England.

Hawes, M. L. 1977. Home range, territoriality, and ecological separation in sympatric shrews, Sorex vagrans and $\mathrm{So}$ rex obscurus. Journal of Mammalogy 58:354-367.

Hayne, D. W. 1949. Calculation of size of home range. Journal of Mammalogy 30:1-18.

Heinrich, B. 1976. Bumblebee foraging and the economics of sociality. American Scientist 64:384-395.

Hogg, R. V., and A. T. Craig. 1978. Introduction to mathematical statistics. Macmillan, New York, New York, USA.

Janzen, D. H. 1971. Euglossine bees as long-distance pollinators of tropical plants. Science 171:203-205.

Jennrich, R. I., and F. B. Turner. 1969. Measurement of non-circular home range. Journal of Theoretical Biology 22:227-237.

Kleiber, M. 1975. The fire of life. R. E. Kreiger, New York, New York, USA.

Koeppl, J. W., N. A. Slade, K. Harris, and R. S. Hoffmann. 1977. A three-dimensional home range model. Journal of Mammalogy 58:213-220.

Koeppl, J. W., N. A. Slade, and R. S. Hoffmann. 1975. A bivariate home range model with possible application to ethological data analysis. Journal of Mammalogy 56:8190.

Lindstedt, S. L., and W. A. Calder III. 1981. Body size, physiological time, and longevity of homeothermic animals. Quarterly Review of Biology 56:1-16.

Manning, A. 1956. Some aspects of the foraging behaviour of bumblebees. Behaviour 9:164-201.

Metzgar, L. H. 1972. The measurement of home range shape. Journal of Wildlife Management 36:643-645.

Mitani, J. C., and P. S. Rodman. 1979. Territoriality: the relation of ranging pattern and home range size to defendability, with an analysis of territoriality among primate species. Behavioral Ecology and Sociobiology 5:241-251.

Pyke, G. H. 1978. Optimal foraging: movement patterns of bumblebees between inflorescences. Theoretical Population Biology 13:72-98.

Schoener, T. W. 1981. An empirically based estimate of home range. Theoretical Population Biology 20:281-325.

Stickel, L. F. 1954. A comparison of certain methods of measuring ranges of small mammals. Journal of Mammalogy 35:1-15.

von Neumann, J. 1941. Distribution of the ratio of the mean square successive difference to the variance. Annals of Mathematical Statistics 12:367-395.

von Neumann, J., R. H. Kent, H. R. Bellinson, and B. I. Hart. 1941. The mean square successive difference. Annals of Mathematical Statistics 12:153-162.

Wierzbowska, T. 1975. Review of methods for estimating the parameters of the home range of small forest rodents from the aspect of sample size. Acta Theriologica 20:3-22. 